\title{
Exploration and Practice of the Practical Teaching Curriculum System for Cultivating Applied and Innovative Undergraduate Talents
}

\author{
Chunhua He, Haiyan Zhang, Aixiang Wei \\ Faculty of Material and Energy, Guangdong University of Technology, Guangzhou, Guangdong, P.R.China
}

Received 2012

\begin{abstract}
Aiming at shortcomings in the current system of practice teaching in high schools especially in regional high schools, a system of practice teaching that fit current cultivation of practical and innovative talents is explored in education. In accordance with the progressive regularity of ability cultivation, the system of practice teaching is divided into four levels: basic practice, basic experiment, advanced practice and comprehensive innovation. And this characteristic system of practice teaching is built up to cultivate practical and innovative talents in grassroots who can meet the requirements of current socio-economic development.
\end{abstract}

Keywords: Cultivation of Practical and Innovative Talents; Practice Teaching; Education Reform

\section{Introduction}

In order to speed up the transformation of economic development, promote scientific development, build up a modern industrial system, promote industrial structure optimization and upgrading, improve the ability of innovation, and take the initiative in fierce competition of globalization, the application of cultivation of practical and innovative talents must be accelerated. In other words, we should focus on promotion of industry adjustment and economic transformation and upgrading. And we should vigorously cultivate specialized talents who can transform and upgrade traditional industries and develop advanced manufacturing industry, service industry and strategic emerging industries. Then we can build up a large team of high-quality talents for modern industry.

Practical ability is the foundation of talent cultivation of practical and innovative undergraduate. In the talent cultivation of practical and innovative undergraduate in colleges and universities, especially in regional colleges and universities, practice teaching has been an important part of education and a basic teaching link for cultivating qualified talents. Besides, practice teaching has a unique affect in ability cultivation and comprehensive quality improvement. Via practice teaching, students will improve their ability of practice, ability of analyzing and solving problems, correct thinking pattern and rigorous scientific attitude and style of work [1]. Aiming at cultivating talents for social and economy development in the new era, it is necessary to carry out new exploration in practice teaching system for talent cultivation of practical and innovative undergraduate, and continually reform, innovate and deepen in the long-term process of teaching practice in order to achieve better effects.

\section{Connotations and Capacity Characteristics of Practical and Innocative Talents}

The so-called practical and innovative talents are people who have strong ability of teaching oneself, ability of job adaptability, ability of technology innovation and re-development, and people who have innovative sense, innovative spirit and innovative ability [2].

\section{Connotations of Practical and Innovative Talents}

Practical and innovative talents are different from academic research talents who are trained under the elite educational philosophy, as well as skilled practical talents who are trained in vocational school. They are between those two kinds of talents, and not purely academic or skilled. In other words, they have to taking into account both sides. This kind of talents must focus on cultivation of practical ability and innovative spirit at the same time. The greatest feature of them is that they have strong ability of technical thought and they are good at application of technology. They can convert knowledge into productivity, re-develop products and solve specific problems in the production. In conclusion, they are people who convert, implement, achieve and innovate in knowledge and technology [3].

\section{Capacity Characteristics of Practical and Innovative Talents}

Practical and innovative talents mainly serve in the forefront of production and management, so that they are highly demanded in abilities and qualities, which include [4]:

1) Possessing foundation of theory: The knowledge for practical and innovative talents should be application-based, and be focused on usefulness. The principle of basic theory is just sufficiency, while the requirements for practical knowledge and skills should attract more attention.

2) Practical operating ability: One of the differences between practical and innovative talents and other kinds of talents is that: they have strong abilities of practice and operating, and they can rapidly meet requirements of job, solve practical 
problems, sensitively discover potential problems in the front line of production, management and service, and solves these problems in the scene by using all kind of knowledge and skills skillfully.

3) Ability of continual innovation: The target for innovative talents in high education stage should be focused on cultivation and improvement of innovative spirit and innovative ability. Because innovative spirit is a strong and enduring motion for people undertake creative works, and it helps individual to solve all kinds of problems in work.

4) Ability of teamwork and cooperation: Practical and innovative talents are mostly in the forefront of production. They are facing design, planning, decision-making and application in the work all the time. And none of those can be done by individual's ability, so creation and cooperation of team are needed. Therefore, spirit of teamwork such as trust, credit, cooperation, and the understanding is an essential quality for practical and innovative talents. And that requires students in college to master a wide range of practical management capabilities, such as communication, association, coordination, organization and leadership.

5) Ability of self-study: A lot of practice can certificate that, knowledge we learned in colleges and universities only accounted for $10 \%$ of knowledge we need in work, while $90 \%$ comes from self-study. Especially to practical and innovative talents, they mostly contact comprehensive field with more complex factors instead of single problem in work, and may be involved in all kinds of aspects. Therefore, practical and innovative talents should focus on coordinated development of KAQ (knowledge, ability, quality), and possess stronger ability of self-study and job adaptability than skilled practical talents, so that they can meet the requirement for generalist by modern enterprise.

\section{The Problems of the Existing System of Practice Teaching}

In current practice teaching system, the proportion of practice for cognition verification is quite large. Most practice teaching is finished step by step in laboratory in accordance with procedure of experiment or curriculum design instructions, which is seriously out of line with actual production. Students are in a passive state when in the link of practice teaching, and lack of integrated design, professional experimental courses and practicum for innovation study, and innovative experiment. The problems of the existing system of practice teaching are embodied in the following aspects:

1) Experimental teaching subordinate to theory classes, which leads to insufficient attention paid by teachers and students: Now experimental classes basically belong to corresponding course, and operating methods of experiments are not very theoretical. Normally, operating methods in the guiding books are detailed, so students absolutely have the ability to complete the required experiments by themselves under the guidance of their teachers. Even if students have no preparation in advance, the experiment will still proceed smoothly, and the data processing and report arranging will be quite well. However, students seldom raise questions and analyze the results of the experiment. Even some students have an incorrect idea that experiment classes are unimportant and easy to pass, which leads to unsatisfactory effects of experiment classes and failure to cultivating ability of independent thinking and innovation.
2) The link of practice teaching is out of touch with the engineering and becomes formality:Because of the constraints of time, space and funding, cognition practice and production practice, which have close contact with the engineering, also become a hurry glance over things. As a result, cognition practice and production practice can hardly achieve their effect, and become formality.

3) The links of practice teaching are separated, so the continuity of students' knowledge is poor: Now experiment, practice and graduation design are separated, and they are basically a combination of courses. Even if for graduation design and thesis, there are only a few practice courses. This kind of system can not efficiently cultivate students' comprehensive ability via practice, let alone innovation ability.

4) More attention are paid on theory than practice, and investment is too less, so practice teaching is depressed: Long-term inertial thinking and relative scarcity of school funds lead to relative lack of investment in education funds, especially in practice teaching funds, and equipment update too slowly. Internship funding hasn't grown for many years, and teachers for experiment practice teaching and management are not very enthusiastic, so practice teaching is always in low levels. All of these have effected the cultivation of innovation ability and practice ability, and finally generate many students who has high scores but low abilities, who are poor at or lazy in practice, and who can not meet the requirement of job after graduation.

\section{Practice Teaching System Reform with Cultivation of Application and Innovation Ability as the Center}

The link of practice teaching is quite important to promote the combination of structure of knowledge, structure of ability and scientific thinking, and it has a special place in cultivation of innovation ability. As an engineering oriented university, cultivating students is to serve territorial social and economy development. Cultivation of advanced technology and engineering ability should be strengthened, and the key of the building of the curriculum should be solving engineering problems. Therefore, we must give prominence to practice teaching, be strict to engineer practice, and emphasize cultivation of manipulative ability. And cultivation of knowledge and ability should be promoted through practice teaching in different stages.

According to the ability requirements of the current society and economy development for practical and innovative talents, the Faculty of Materials and Energy of Guangdong University of Technology has reformed practice teaching, and the setting of system is shown in Figure 1. In accordance with the progressive regularity of ability cultivation, the system of practice teaching is divided into four levels: basic practice, basic experiment, advanced practice and comprehensive innovation. In the whole system of practice teaching, research projects for students, innovation projects for students, subject contests and experiments of comprehensive innovation are throughout the process of practice teaching.

\section{Level of Basic Practice}

The level of basic practice includes engineering practice, internship of computer application software, basic course experiment, cognition practice and society survey. It focuses on 
cultivation of basic skill and experiment skill, and improvement of basic capacity. Through society survey students can understand the requirement for talents' ability in the industry. Through internship of software students can understand the software used frequently in profession courses and work, for example, AutoCAD, UG, PRO/Engineer, Protel DXP and so on, and master the basic application of such software. In fact, many enterprises require applicants to master computer language and operating skills for many platforms. At the same time, students can learn advanced methods for experiments, which can be a foundation of professional courses.

\section{Level of Basic Experiment}

The level of basic experiment focuses on improving the ability of combining theory and practice. Except the necessary experiments set for simply verifying the theory, most experiment classes are separated from theory classes to break the boundaries between different subjects. Experiment class is independently set in accordance with subject type. And it is also treated and arranged as an independent subject to broaden the field of practical teaching. The connection and combination of logic and structure in experiment class of different subjects are improved, so the target of entirety optimization can be achieved. By all of these, the curriculum can maintain a connection from beginning to ending, and proceed step by step. Thus experiment class can be an intrinsically linked organized whole, which goes from the easy to the difficult and complicated and spires. Course experiment of some related subjects, such as metal material engineering, materials processing engineering and electronic information materials and components, are integrated and optimized, and is set together.

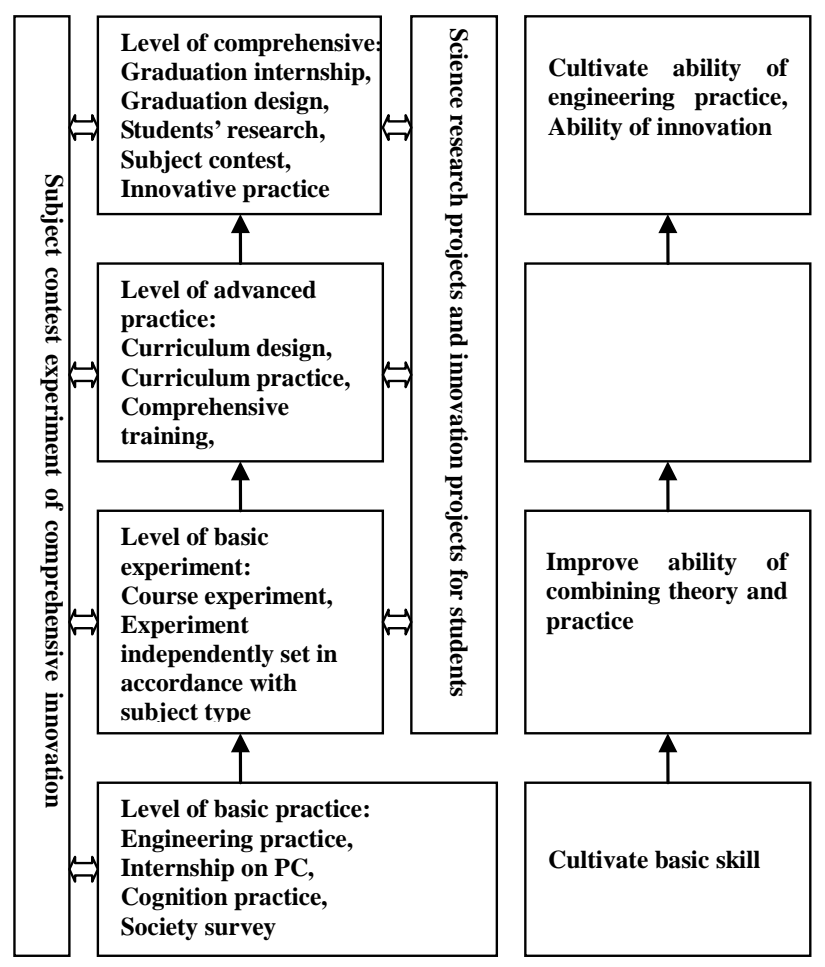

Figure 1.

System of practice teaching

\section{Level of Advanced Practice}

The level of advanced practice includes professional training, engineering practice project, curriculum design, comprehensive and innovative experiment, production practice and cultivation project of colleges and enterprises. It is the main part of engineering ability cultivation for students, which focuses on cultivation of specialized characteristic for students. And it mainly cultivates ability of comprehensive design, ability of teamwork and preliminary ability of innovation practice, so that students can establish a sense of innovation and engineering awareness in early time, and feel a sense of achievement.

An example is the semiconductor device manufacturing process experiment of Microelectronics. First, silicon samples will be manufactured by material preparation technology and tested in sheet resistance experiment. Then, oxidation experiment, lithographic experiment and boron diffusion experiment will be conducted and through these the PN junction diode will be manufactured. At last, the I-V characteristics and breakdown voltage of PN junction will be tested. All of these can develop students' interest in learning, strengthen the student's responsibility, enhance of integrity and synthesis of the experiment, and make the learning coherent and connecting.

Another example is mold experiment of material forming and controlling specialty. Every student will join in the whole procedure including product design, mold design, mold manufacture, mold assembly, mold debugging and purchasing material, standard parts, cutting tools, measuring tools and instrument for mold manufacture. Therefore, students can understand and master the whole process for mold parts including purchase, mechanical workout, assembly and mold test.

Figure 2 shows parts of students' work from comprehensive and innovative experiments.

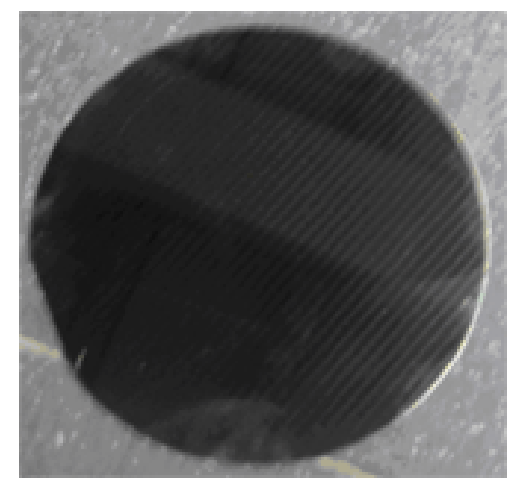

(a) diode lithographed on silicon

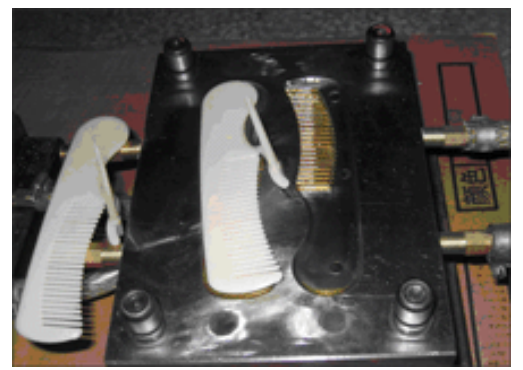

(b) experiment work of injection molding

Figure 2.

Display of students' work. 


\section{Level of Comprehensive Innovation}

The level of comprehensive innovation includes all kinds of research training, graduation internship, graduation design, students' research project and technological innovation activities. And it can further cultivate students' ability of research, ability of engineering practice and ability of innovation. The research projects are of practical value, or from the front line of research and production, or related to enterprise or research projects of teachers. So students can fulfill the whole training process from product design, process development, product molding to product quality test. Some graduation designs use training mode of order form according to enterprises' requirements: students will practice directly in enterprise since the production practice in the seventh term, and make their quests of graduation design (finish in enterprise) according to enterprises' requirements in the eighth term.

As for the cultivation of innovation ability, students are encouraged to participate in the various competitions for national college students, such as mathematical modeling competition, electronic design competition, computer simulation competition, structural design competition, the business plan competition, robotics competition, learning competition, Challenge Cup and so on.

Figure 3 shows parts of students' design from electronic competition and science and technology innovative activities.

The characteristics of practice teaching system above-mentioned are:

- More attention is paid on combining practice teaching with actual production, research, extracurricular science and technology innovation and social practice.

- The choice of practice contends reflects comprehensiveness, characteristic of design and research, and it helps to cultivate students' knowledge proficiency and ability of innovation.

- The autonomy of the students is prominent, while teachers are changed from counselors of practice teaching activity to guides of students' practice activity. It helps to cultivate students' ability of practice, ability of solving practical problems and spirit of teamwork.

\section{Summary}

Practice is the foundation of innovation, so that practice teaching of undergraduate is an important part of cultivation of practical and innovative talents. Now the research and exploration of practice teaching mode in the Faculty of Materials and Energy of Guangdong University of Technology has achieved initial success. However, continuous exploration and reform of practice are needed to improve the quality of practice teaching, and to cultivate more practical and innovative talents who can meet the requirements of socio-economic development in the new era. In the next step, an important mission is to build up a

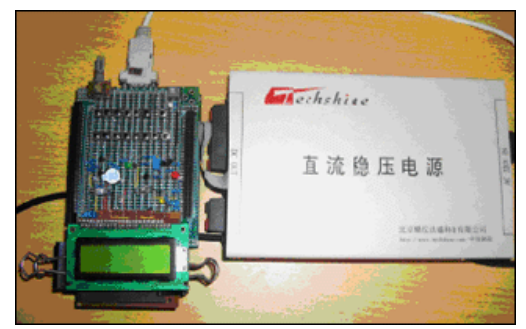

(a) IC card intelligent charging system

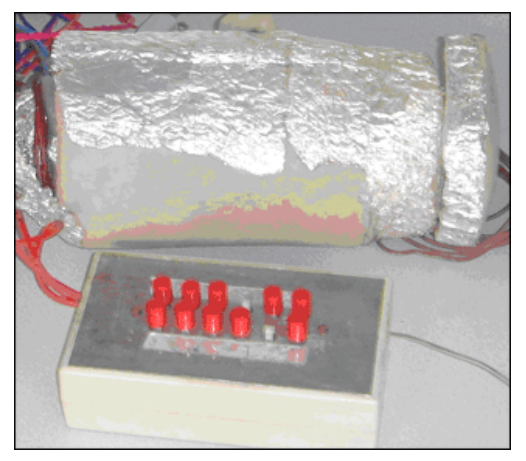

(b) determinator for ground thermal conductivity

\section{Figure 3.}

Students' work from electronic competition and science and technology innovative.

practice environment with more comprehensiveness, characteristic of design and creativity for as more students as we can, so that every college student can cultivation in different links of practice at the undergraduate. And as for the content of practice teaching, links of practice with more characteristic of exploration and research should be added, on order to mobilize students' enthusiasm and initiative, stimulate students' creative thinking, and further improve students' ability of engineering practice, innovation ability and comprehensive ability.

\section{REFERENCES}

J. F. Shi, "The Strategic Thinking to the Construction of the Training System of the Applied Innovative Talent,” MEITAN Higher Education, Vol. 26, pp. 29-31, July 2008.

H. Z. Xiao, "The cultivating pattern of applicative and innovative talents,” Journal of Liaoning Technical University(Social Science Edition), vol. 10, pp. 208-210, Mar 2008.

L. Jia, "Study of building practical teaching management system for applied and innovative talents," Higher Agricultural Education, Vol. 227, pp. 29-32, May 2010.

G. H. Zhou, "Strategies of Cultivating the Applied and Innovative Personnel in Local Institutes of Engineering,” Journal of Huaiyin Institute of Technology, vol. 16, pp. 72-75, Dec 2007. 